\title{
Development of a Specific Anti-capsid Antibody- and Magnetic Bead-Based Immunoassay to Detect Human Norovirus Particles in Stool Samples and Spiked Mussels via Flow Cytometry
}

\author{
Ravo M. Razafimahefa ${ }^{1} \cdot$ Louisa F. Ludwig-Begall $^{1}$ Mamadou Amadou Diallo ${ }^{2}$. Benjamin G. Dewals ${ }^{2}$. \\ Alain Vanderplasschen ${ }^{2} \cdot$ Olivier Nivelles $^{2} \cdot$ Caroline Deketelaere $^{2} \cdot$ Axel Mauroy $^{3} \cdot$ Etienne Thiry $^{1}(0)$
}

Received: 27 April 2021 / Accepted: 28 July 2021

(c) The Author(s), under exclusive licence to Springer Science+Business Media, LLC, part of Springer Nature 2021

\begin{abstract}
Human noroviruses impose a considerable health burden globally. Here, a flow cytometry approach designed for their detection in biological waste and food samples was developed using antibody-coated magnetic beads. Antipeptide antibodies against murine norovirus and various human norovirus genotypes were generated for capture and coated onto magnetic beads. A flow cytometry assay was then implemented to detect bead-bound human norovirus GI.3 in patient stool samples and in norovirus-spiked mussel digestive tissues. The detection limit for stool samples was $10^{5} \mathrm{gc} / \mathrm{mL}$, thus bettering detection limits of commercially available norovirus diagnosis quick kits of 100-fold; the detection limit in spiked mussels however was tenfold higher than in stool samples. Further assays showed a decrease in fluorescence intensity for heat- or UV-inactivated virus particles. Overall, we demonstrate the application of a flow cytometry approach for direct detection of small non-enveloped virus particles such as noroviruses. An adaptation of the technology to routine diagnostics has the potential to contribute a rapid and sensitive tool to norovirus outbreak investigations. Further improvements to the method, notably decreasing the detection limit of the approach, may allow the analysis of naturally contaminated food and environmental samples.
\end{abstract}

\section{Graphic Abstract}

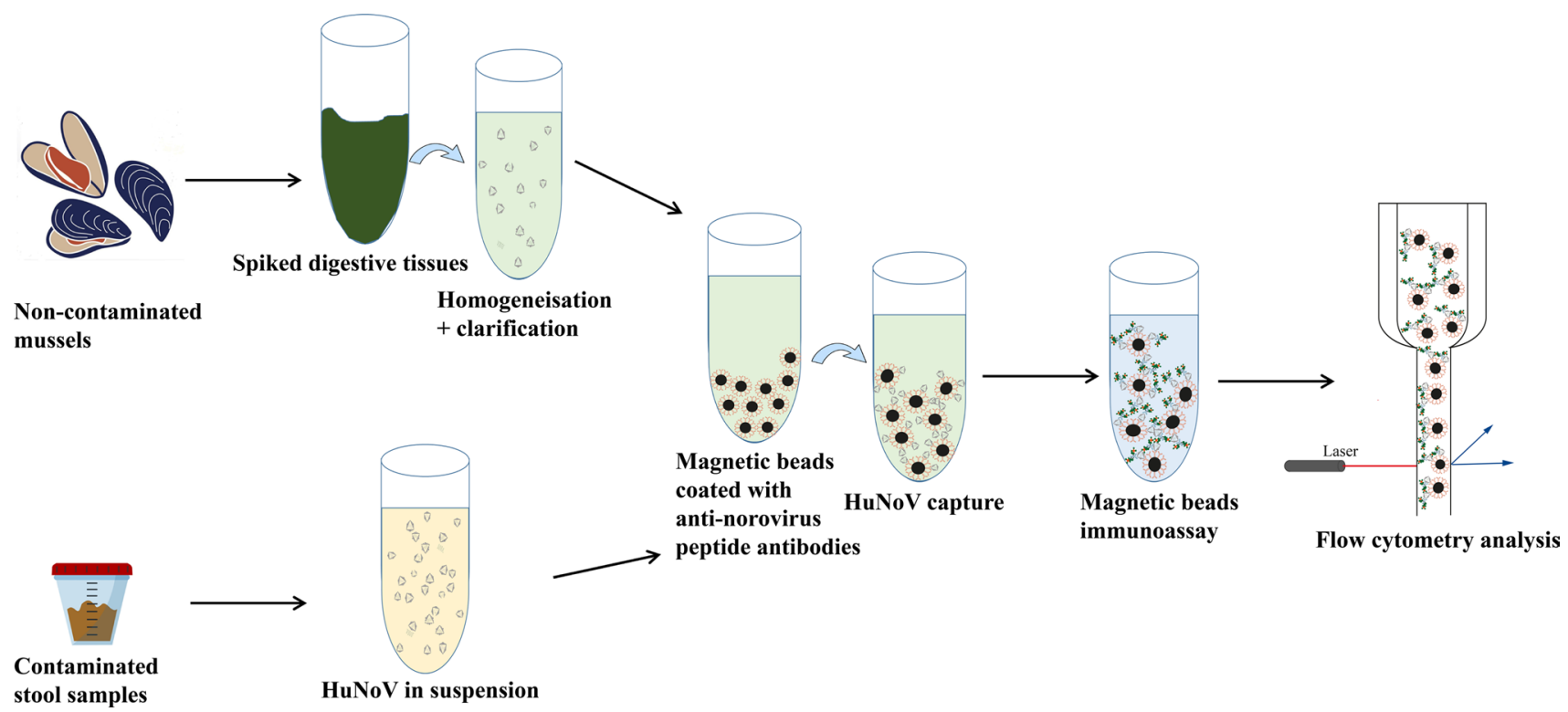

Keywords Flow cytometry $\cdot$ Magnetic bead-based immunoassay $\cdot$ Norovirus $\cdot$ Stool samples $\cdot$ Mussels

Extended author information available on the last page of the article 


\section{Introduction}

Noroviruses (NoVs) were first identified in Norwalk, Ohio (United States of America) in 1968 as the cause of epidemic gastroenteritis in an elementary school (Kapikian et al., 1972). Four years later, identification was carried out by electron microscopy analyses of infectious stool filtrates from affected persons during the outbreak. NoVs are now recognised as one of the major global causes of gastrointestinal illness and the major cause of viral foodborne illness; their rapid detection is incremental to outbreak control (Glass et al., 2009; Mead et al., 1999). Noroviruses belong to Caliciviridae family of non-enveloped, positive-sense, single-stranded RNA viruses (Dolin et al., 1972). Norovirus RNA is 7.5 to $7.7 \mathrm{kbp}$ in length and consists of three open reading frames (ORFs) (Lambden et al., 1993). ORF1 encodes six non-structural proteins, from the $\mathrm{N}$ terminus to $\mathrm{C}$ terminus: $\mathrm{p} 48$, nucleoside-triphosphatase (NTPase), p22, VPg, 3C-like protease (3CLpro) and the RNA-dependent RNA polymerase (RdRp) (Hardy, 2005). ORF2 and ORF3 encode the major (VP1) and minor (VP2) capsid proteins, respectively (Jiang et al., 1992). VP1 is further divided into two major hinge-linked $\mathrm{S}$ and $\mathrm{P}$ domains, both of which are recognised by NoV antibodies (Li et al., 2009, 2010; Mallory et al., 2019; Parra et al., 2013; Yoda et al., 2003). The S domain (residues 1 to 217), demonstrated to be the most conserved VP1 region (Prasad et al., 1999), is responsible for capsid assembly. The C-terminal P domain (residues 226 to 530), composed of subdomain P1 and hypervariable subdomain P2 (residues 275 to 405), forms arch-like structures extending from the shell (Prasad et al., 1999); P2 has an important role in immune recognition and receptor interaction (Tan et al., 2008). Several monoclonal antibodies (mAbs) targeting epitopes in the inner shell or $\mathrm{S}$ domain have been shown to be broadly reactive across different human and animal norovirus strains (Li et al., 2009, 2010; Parra et al., 2013; Yoda et al., 2003). Li et al. (2009) previously generated three mAbs from a $60 \mathrm{kDa}$ full-length recombinant capsid protein of norovirus GII.4 expressed in Escherichia coli; of these, the broadly cross-reactive mAb N2C 3 targeted the conserved epitope WIRNNF (six residues of the S domain; position 55-60). Parra et al. (2013) described mAb TV20, a broadly cross-reactive mAb generated from GII.3 HuNoV VLPs that recognises an epitope of five residues of the $\mathrm{S}$ domain (IDPWI; 52-56).

The mutations and frequent recombination of NoVs create high genetic variability (Ludwig-Begall et al., 2018), which poses a major problem for the production of cross-reactive vaccines and for efficient NoV detection with broadly reactive antibodies. Noroviruses are divided into ten genogroups according to the sequence homology of VP1 (Chhabra et al., 2019). GI, GII, GIV,
GVIII and GIX viruses infect humans. These genogroups are subdivided into genotypes: GI $(n=9)$, GII $(n=27)$, GIV $(n=2)$, GVIII $(n=1)$ and GIX $(n=1)$ (Chhabra et al., 2019). GII.4-related strains are the most prevalent strains worldwide and cause pandemics (Atmar \& Estes, 2006; Siebenga et al., 2009). Recently, the emergence of a new epidemic strain, recombinant GII.4 Sydney (GII.P16-GII.4 Sydney), was highlighted (Ruis et al., 2017).

The flow cytometer is a well-known instrument typically employed to characterise individual cells or to analyse sub-micron particles (Fuller \& Sweedler, 1996; Tracy et al., 2010; Vorauer-Uhl et al., 2000). The main constraint of flow cytometry in its application to the study of viruses is their small size, which limits individual examination. However, certain viruses below the typical detection limits of flow cytometry analyses in size have been successfully identified when labelled with fluorescent dyes; amongst these are Cucumber Mosaic Virus (29 nm) (Iannelli, 1996; Iannelli et al., 1997), influenza virus (80 to $120 \mathrm{~nm}$ ) (Yan et al., 2004, 2005), dengue virus (40 to $60 \mathrm{~nm}$ ) (Zicari et al., 2016) and human rotavirus ( $80 \mathrm{~nm}$ ) (Gozalbo-Rovira et al., 2021). The detection of virus particles via flow cytometry analysis is commonly based on fluorescence, this in conjunction with various methods such as virus detection with antibodies directed against surface antigens (antibodies coupled to beads) (Arakelyan et al., 2013; Iannelli et al., 1997; Kim et al., 2009; Yan et al., 2004, 2005; Yang et al., 2008), envelope labelling (Arakelyan et al., 2013; Tang et al., 2016; Zicari et al., 2016) and genetic material labelling (Brussaard et al., 2000; El Bilali et al., 2017; Loret et al., 2012). Currently, detection and quantification of NoVs is commonly performed by RT-qPCR (ISO 15216-1 2017). First steps towards NoV detection via flow cytometry were recently performed by Madrigal and Jones who used virus-specific antibodies to quantify virus-like particle binding to gramnegative and gram-positive commensal bacteria (Madrigal \& Jones, 2020).

NoV detection via flow cytometry based on magnetic beads requires suitable antibodies for capture and detection. Here, we generated rabbit antipeptide antibodies against an 18-mer peptide containing two previously mentioned epitopes (IDPWI and WIRNNF) in the S domain (Li et al., 2009; Parra et al., 2013) with different levels of reactivity towards eight NoVs, including murine norovirus (MNV) and human norovirus (HuNoV). The amino acid alignment of the 18-mer peptide with representative GI and GII HuNoV genotypes and GV MVN1 is presented in Fig. 1. The antipeptide antibodies were coated onto magnetic beads for NoV capture. Bound NoV particles were then detected using a biotinylated mouse antibody and labelled with streptavidin conjugated to a fluorescent dye (Fig. 2). This approach was applied both to the detection of HuNoV in biological samples (faecal suspension) and in spiked food samples (mussel 
Fig. 1 Sequence alignment of the 18-mer peptide with representatives of GI and GII HuNoVs and GV MNV1. Bold type residues of the peptide represent the epitopes ${ }^{52} \mathrm{IDPWI}^{56}$ and ${ }^{55}$ WIRNNF $^{60}$. Those residues that are shared between both epitopes are represented by a dash 18-mer peptide

KP064095.1

KF049152.1

KX608873.1

KT962983.1

KT239579.2

KC223590.1

KY427670.1

AY228235
50

55

60

65

VNM I D PWI R N N F V Q A P Q G

VNM - - - - V - - VQS PQG

VNM - - - MS - YVQAPQG

NNV - - - - M - VQAPNG

GII.1 HuNoV

GII.2 HuNoV

TN I - - - A - VQAPNG

GII.4 HuNoV

QNV - - . - - VQAPQG

GII.12 HuNoV

N I V - - - - F - VQAPNG

GII.14 HuNoV

TN I - - - T - VQAPNG GV MNV1

Fig. 2 Schematic representation of the flow cytometry approach. A Addition of samples to the antibody-coupled magnetic beads and binding of viruses to capture antibodies. B Binding detection by biotinylated monoclonal antibody directed against NoV. C Addition of PE-Cy5 conjugated streptavidin for fluorescent tagging of bound viruses. D Detection with flow cytometer instrument
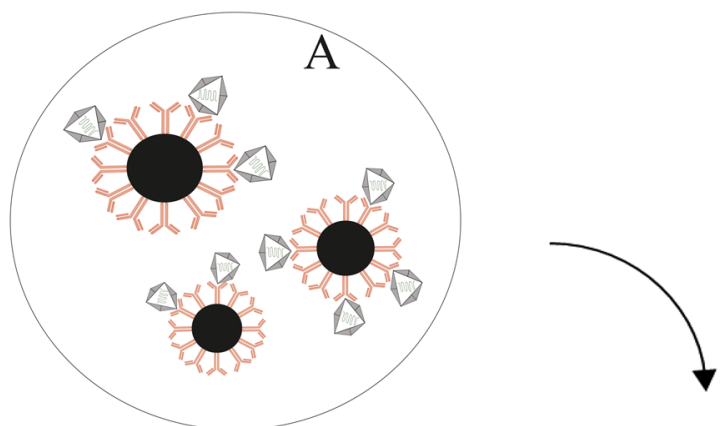

Addition of samples and viruses binding to antipeptide antibodies

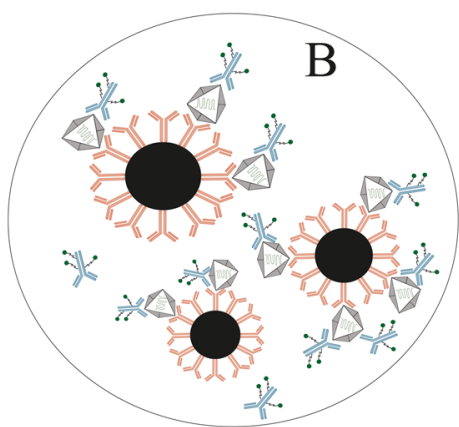

Detection with flow cytometer

Addition of biotinylated monoclonal antibodies and binding to the complex virus-antipeptide antibody-beads
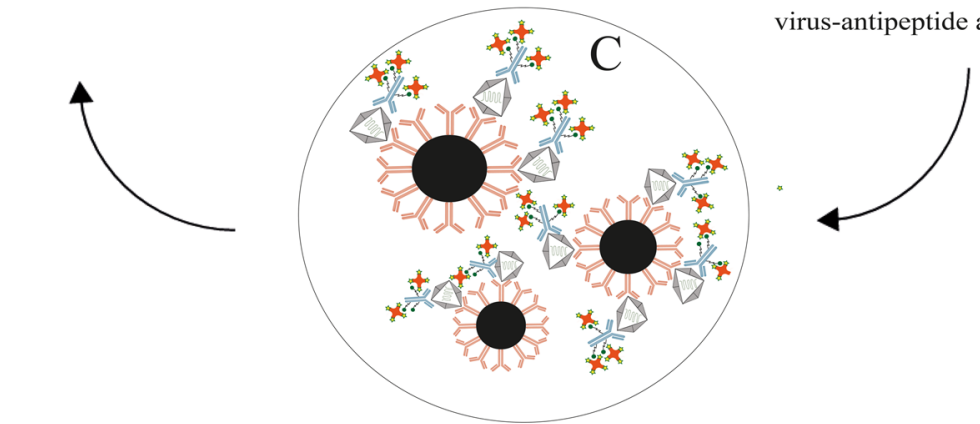

Addition of the PE-Cy5 conjugated streptavidin for fluorescent tagging of bound viruses

Magnetic bead

Biotin \& \&E-Cy5

Human norovirus

Monoclonal antibody $\rightarrow$ Streptavidin 
digestive tissues (DTs)), where the coated magnetic beads served to isolate virus particles from a more complex matrix.

\section{Materials and Methods}

\section{Ethics Statement}

Animal experiments and the production of anti-peptide antibodies were approved by the Animal ethics commission of Liège University (protocol number 1598).

\section{Viruses and Cells}

\section{Cell Culture}

RAW 264.7 (ATCC TIB-71) cells were grown at $37{ }^{\circ} \mathrm{C}$ with $5 \%$ of $\mathrm{CO}_{2}$ in Dulbecco's Minimal Essential Medium (DMEM), supplemented with $10 \%$ foetal calf serum, $2 \%$ of penicillin $(10,000$ units $/ \mathrm{mL})$ - streptomycin $(50 \mathrm{mg} /$ $\mathrm{mL}$ ) (Invitrogen), 1\% of non-essential amino acids and 1\% HEPES buffer (pH 7.6) (Invitrogen).

\section{Viruses}

MNV isolate MNV-1 CW1 (Thackray et al., 2007) was propagated in RAW 264.7 cells (starting MOI 0.05; 3-day incubation). For virus purification, flasks were first subjected to three freeze-thaw cycles. To remove cell debris, cultured MNV suspensions were centrifuged at $4000 \times g$ for $10 \mathrm{~min}$ at $4{ }^{\circ} \mathrm{C}$. Supernatants were transferred to a new tube and a $5 \mathrm{~mL}$ sucrose cushion ( $30 \% \mathrm{w} / \mathrm{v}$ in PBS) was layered under each supernatant prior to ultracentrifugation $23,000 \times g$ for $1.5 \mathrm{~h}$ at $4{ }^{\circ} \mathrm{C}$. The supernatants were discarded and pellets were suspended in PBS and kept at $-80^{\circ} \mathrm{C}$ until use.

Faecal specimens testing positive for $\mathrm{HuNoV}$ were obtained from Dr Pascale Huynen (Centre Hospitalier Universitaire, Liège, Belgium) and Dr Katelijne Dierick (Sciensano, NRL for the diagnosis of HuNoV infections, Brussels, Belgium) (Table 1). Stool samples were diluted in PBS (to obtain $10 \% \mathrm{w} / \mathrm{v}$ preparation), briefly vortexed and centrifuged twice at $1500 \times g$ for $10 \mathrm{~min}$ and once at $5000 \times g$ for $10 \mathrm{~min}$. The supernatant was stored at $-80{ }^{\circ} \mathrm{C}$ until use.

\section{Titration of Viruses $\left(T C I D_{50}\right.$ assay $)$}

Infectivity of MNV-1 CW1 was determined via TCID $_{50}$ assay. Briefly, RAW 264.7 cells were seeded in a 96-well plate at a concentration of $4.10^{4}$ cells per well. Plates were incubated at $37{ }^{\circ} \mathrm{C}$ with $5 \% \mathrm{CO}_{2}$ for at least $2 \mathrm{~h}$ before infection to allow cells to attach. Serial tenfold virus dilutions were prepared and added to the wells.
Table 1 Human norovirus sample characteristics

\begin{tabular}{lll}
\hline Genogroups & Genotypes & $\mathrm{Ct}$ \\
\hline GII & GII.1 & 23.22 \\
GII & GII.13 & 20.21 \\
GII & GII.14 & 17.58 \\
GI & GI.1 & 30 \\
GII & GII.2 & 19.39 \\
GII & GII.12 & 23.66 \\
GI & GI.2 & 22.92 \\
GII & GII.4 Sydney & 18.27 \\
GI & GI.3 & 17 \\
\hline
\end{tabular}

After three days of incubation at $37{ }^{\circ} \mathrm{C}$ with $5 \% \mathrm{CO}_{2}$, plates were examined under the microscope and wells showing cells with cytopathic effects (CPE) for each dilution were counted. The Reed and Muench (1938) method was applied to express the infectivity as $\operatorname{TCID}_{50} /$ $\mathrm{mL}$. Each sample was analysed three times for technical replicates.

\section{Inactivation Treatments}

For heat inactivation, sealed tubes with $400-500 \mu \mathrm{L}$ of HuNoV suspension were immersed in a $90{ }^{\circ} \mathrm{C}$ hot water bath for 2 min and were directly cooled on ice.

For UV-inactivation, $400-500 \mu \mathrm{L}$ aliquots of $\mathrm{HuNoV}$ suspension in transparent $1.5 \mathrm{ml}$ Eppendorf tubes were irradiated for $1 \mathrm{~h}$ with an R-52 Grid Lamp (UVP), which emits a uniform $254 \mathrm{~nm}$ high-intensity UV source (200-250 V, 50/60 Hz, 45 AMPS).

\section{Artificial Contamination of Mussel DTs by Spiking}

Fresh mussels (Mytilus edulis) were purchased at a local fish shop. Mussels were directly dissected upon arrival at the laboratory. The adductor muscle was first cut to open the mussels'; digestive tissues were then removed and kept at $-80{ }^{\circ} \mathrm{C}$ before spiking or analysis. For artificial contamination, $1 \mathrm{~g}$ of DTs was spiked with heat- or UV-inactivated or non-inactivated HuNoV GI.3. Non-spiked mussel DTs were included as negative controls. The spiked mussel DTs were homogenised using a TissueLyser (Qiagen) with a stainless-steel bead $(5 \mathrm{~mm})$ at $30 \mathrm{~Hz}$ for $2 \mathrm{~min}$. Supernatants were recovered after centrifugation at $3000 \times g 5 \mathrm{~min}$ and $5000 \times g 10 \mathrm{~min}$. To determine the LoD in mussel DTs, tenfold serial dilutions of HuNoV GI.3 were performed in mussel DT homogenates. 


\section{RT-qPCR Analyses}

RNA was extracted from $100 \mu \mathrm{L}$ purified viral suspension using the QIAamp Viral RNA Mini Kit (Qiagen, Valencia, CA, USA) and implementing the spin protocol as per the manufacturer's instructions. The nucleic acid was eluted into $50 \mu \mathrm{L}$ elution buffer and stored at $-20{ }^{\circ} \mathrm{C}$ for subsequent analysis.

Primers and probes for the individual quantification of GI and GII NoVs by RT-qPCR were designed by the CEN/ TC/WG6/TAG4 research group (Loisy et al., 2005; Svraka et al., 2007). An overview of the primer and probe sequences is shown in Table 2. All primers and probes were purchased from IDT (Belgium).

The RT-qPCR one-step reaction was performed with an RNA Ultrasense ${ }^{\mathrm{TM}}$ one-step quantitative RT-PCR system (Invitrogen) in a $25 \mu \mathrm{L}$ reaction volume containing $5 \mu \mathrm{L}$ RNA template, $0.2 \mu \mathrm{M}$ each of both forward and reverse primers and the probe (Table 2).

The cycling conditions were as follows: $55^{\circ} \mathrm{C}$ for $15 \mathrm{~min}$, $95{ }^{\circ} \mathrm{C}$ for $1 \mathrm{~min}$, and 40 cycles of $95{ }^{\circ} \mathrm{C}$ for $15 \mathrm{~s}, 60^{\circ} \mathrm{C}$ for $30 \mathrm{~s}$ and $65^{\circ} \mathrm{C}$ for $40 \mathrm{~s}$. The RT-qPCR was performed using a CFX96 Touch $^{\mathrm{TM}}$ Real-Time PCR Detection System (Bio-Rad). The standard curves for the molecular detection of GI NoV were constructed using plasmids containing primer-probe binding sites. Briefly, HuNoV GI ORF1/ORF2 nucleotides 5321 to 5340 were cloned into a pGMT easy vector (Promega). Following transformation into Escherichia coli $\mathrm{DH} 5 \alpha$, clones were screened, and in vitro transcription of positive clones was performed with linearised plasmid samples using the HiScribe T7 Quick High Yield RNA Synthesis Kit (BioLabs). After DNase treatment, in vitro transcribed RNA was purified and quantified using the Quant-iT ${ }^{\mathrm{TM}}$ RiboGreen $^{\mathrm{TM}}$ RNA Assay Kit (Invitrogen).

\section{Reagents}

Monoclonal mouse-antibodies L34D (ref. MA5-18241, Thermofisher) and S57S (ref. MA5-18237, Thermofisher) were used as detection antibodies for HuNoV GII and GI, respectively. Both mAbs have been tested by western blot, ELISA and lateral flow analysis according to the manufacturer.

Carboxyl magnetic beads between 5 and $5.9 \mu \mathrm{m}$ in diameter (mean size: $5.72 \mu \mathrm{m}$ ) were used (Spherotech, LibertyVille, IL). 1-ethyl-3-(3-dimethylaminopropyl) carbodiimide hydrochloride (EDC) and N-hydroxysuccinimide (NHS) were purchased from Sigma-Aldrich (St. Louis, MO, USA).

\section{Production and Purification of Antipeptide Antibodies}

Two S domain epitopes, IDPWI and WIRNNF, identified by Parra et al. (2013) and Li et al. (2010), respectively, were selected since monoclonal antibodies targeting these epitopes have been shown to be broadly reactive; in addition, the $\mathrm{S}$ domain is known as a conserved region in the NoV capsid. A peptide encompassing 18 amino acids (VNMIDPWIRNNFVQAPQG) of the NoV capsid protein containing these two epitopes was synthetised and conjugated with a immunogen keyhole limpet haemocyanin (KLH) carrier by Eurogentec (Liège, Belgium). Two rabbits were injected four times over a 12-week time period. The rabbits were first immunised intraperitoneally with $1 \mathrm{mg}$ of peptide-KLH in an equal volume of Freund's complete adjuvant (priming). Fourteen days later, they were boosted with $0.5 \mathrm{mg}$ of peptide-KLH in an equal volume of Freund's incomplete adjuvant; this was performed twice at 14-day intervals. Next, the sera were collected from immunised rabbits and were assayed for antibody production against the immunising

Table 2 Oligonucleotide primer and probe sequences used to detect viruses belonging to human norovirus genogroups I and II (GI and GII) via real-time TaqMan RT-PCR

\begin{tabular}{lcc}
\hline Primer and probe sequences $\left(5^{\prime} \rightarrow 3^{\prime}\right)$ & Product length (in base pairs, bp) (Position) & $\begin{array}{c}\text { Final concentra- } \\
\text { tion }(\mathrm{nM})\end{array}$ \\
\hline HuNoV GI & $86(5291-5376)$ & \\
QNIF4: CGCTGGATGCGNTTCCAT (F) & $(5321-5340)$ & 200 \\
NV1LCR: CCTTAGACGCCATCATCATTTAC (R) & & 200 \\
NV1LCpr: FAM-TGGACAGGAGAYCGCRATCT-BHQ (p) & $89(5012-5100)$ \\
Sequence and positions based on the sequence of Norwalk virus 8FIIa strain (GenBank accession no. M87661.1) (where N is A, C, G, or T and \\
Y is C or T and R is A or G) (Le Guyader et al., 2009) \\
HuNoV GII \\
$\begin{array}{l}\text { QNIF2: ATGTTCAGRTGGATGAGRTTCTCWGA (F) } \\
\text { COG2R: TCGACGCCATCTTCA TTCACA (R) }\end{array}$ \\
QNIFs: FAM-AGCACGTGGGAGGGCGATCG-BHQ (p) \\
Sequence and positions based on the sequence of GII.4 Houston strain (GenBank accession number EU310927) (where R is A or G and W is \\
A or T) (Le Guyader et al., 2009)
\end{tabular}


antigens in an ELISA assay. Seropositive rabbits were given a final boost immunisation prior to a final bleeding.

Both R2 and R12 sera were purified with Protein A (Pierce ${ }^{\mathrm{TM}}$ Protein A Agarose, ref. 20334) using Pierce Spin Columns and elution buffer from the Pierce ${ }^{\mathrm{TM}}$ Co-Immunoprecipitation Kit (ref. 26149, Invitrogen), following manufacturer's instructions. The IgG antibodies were desalted on PD MidiTrap ${ }^{\mathrm{TM}}$ G-25 Sample Preparation Columns (GE Healthcare) and were suspended in PBS before measurement of antibody concentrations against purified R2 and R12 antipeptides with the Pierce ${ }^{\mathrm{TM}} \mathrm{BCA}$ Protein Assay Kit (ref. 23225).

\section{Indirect ELISA Assay}

The indirect ELISA assay was performed as described by Kolawole et al., (2014) with some modifications as follows. Briefly, an ELISA plate was coated overnight at $4{ }^{\circ} \mathrm{C}$ with $0.020 \mathrm{mg} / \mathrm{mL}$ of MNV-CW1 and HuNoV (previously purified via ultracentrifugation over a sucrose cushion as described above) in coating buffer (carbonate buffer $\mathrm{pH}$ 9.6). For negative controls, wells were coated with coating buffer only. After washing with $0.15 \mathrm{M} \mathrm{NaCl}$ PBS-Tween $0.05 \%$, the plate was blocked for $1.5 \mathrm{~h}$ at $37{ }^{\circ} \mathrm{C}$ with $3 \%$ bovine serum albumin (BSA) in coating buffer. The plate was washed and diluted antipeptide antibodies $(10 \mu \mathrm{g} / \mathrm{mL})$ in ELISA buffer were added. After $1.5 \mathrm{~h}$ of incubation, plates were washed again and $100 \mu \mathrm{L}$ of 1:1000 polyclonal goat anti-rabbit-horseradish peroxidase (HRP) (Invitrogen) was added. The plates were incubated for $2 \mathrm{~h}$ and then washed seven times before addition of $100 \mu \mathrm{L}$ substrate 2,2'-Azinobis 3-thylbenzthiazoline sulfonic acid (ABTS), for $30 \mathrm{~min}$. Plates were read at $405 \mathrm{~nm}$ on an iMark Microplate reader (EnSpire Plate reader).

\section{Sandwich ELISA Assay}

Ninety-six-well plates were coated with $5 \mu \mathrm{g} / \mathrm{mL}$ R2 antipeptide antibodies diluted in coating buffer and were left overnight at $4{ }^{\circ} \mathrm{C}$; for negative controls, wells were coated with coating buffer only. Each well was blocked with $3 \%$ BSA in coating buffer for $1.5 \mathrm{~h}$ at $37^{\circ} \mathrm{C}$, and then the plates were washed three times with $0.15 \mathrm{M} \mathrm{NaCl}$ PBS-Tween $0.05 \%$. Ten-fold diluted GI.3 or GII.4 or GII.14 in ELISA buffer was added, and the plates were incubated for $1.5 \mathrm{~h}$ at $37^{\circ} \mathrm{C}$. 1:20 ELISA buffer-diluted monoclonal anti-GI NoV antibody S57S or 1:20 diluted monoclonal antibody (mAb) L34D-anti-GII NoV was added and incubated for $1.5 \mathrm{~h}$ at $37^{\circ} \mathrm{C}$. After washing, 1:1000 diluted secondary polyclonal rabbit anti-mouse-HRP (Dako) was added and incubated for $2 \mathrm{~h}$. Plates were washed seven times and the ABTS reagent was added. The signal was detected by measurement of optical density at $405 \mathrm{~nm}$ on an iMark Microplate reader (EnSpire Plate reader).

\section{Immunofluorescence Assay}

RAW 247.6 cells were plated on $18 \mathrm{~mm}$ glass coverslips in 12-well plates and grown overnight. At a confluency of $70 \%$, cells were infected with MNV1-CW1 at a MOI of 0.1 . Twenty hours later, cells were fixed in $4 \%$ (v/v) paraformaldehyde in PBS for 25 min. After washing with PBS, samples were permeabilised in PBS containing $0.1 \%(\mathrm{v} / \mathrm{v})$ Triton $\mathrm{X}-100$ at room temperature for $15 \mathrm{~min}$. Immunofluorescent staining (incubation and washes) was performed in PBS containing 10\% FCS (v/v) and 0.1\% BSA. Antipeptide antibodies were used as the primary antibody at dilution 1:500 (R2 sera) and 1:200 (R12 sera) for $1 \mathrm{~h}$ at room temperature, followed by Alexa Fluor 488 goat anti-mouse immunoglobulin $\mathrm{G}(\mathrm{H}+\mathrm{L})$ (Invitrogen) as the secondary antibody (1:1000 dilution). After washing, cells were mounted using Prolong Gold antifade reagent with Di Aminido Phenyl lndol (DAPI) (Invitrogen). Samples were analysed by confocal microscopy, using a Leica SP5 confocal microscope and compiled using ImageJ Software (Schindelin et al., 2012).

\section{Coupling Antibodies to Beads}

Coupling consisted of coating magnetic beads with R2 antipeptide antibodies. $10^{7}$ beads were activated in $500 \mu \mathrm{L}$ of activation buffer $(10 \mathrm{mM}$ sodium acetate in deionized water $\mathrm{pH}$ 5) with $10 \mu \mathrm{L}$ and $33 \mu \mathrm{L}$ of $\mathrm{N}$-hydroxysuccinimide (NHS $50 \mathrm{mg} / \mathrm{mL}$ ) and $\mathrm{N}$-(3-Dimethylaminopropyl)$\mathrm{N}^{\prime}$-ethylcarbodiimide hydrochloride (EDC $100 \mathrm{mg} / \mathrm{mL}$ ), respectively. NHS and EDC were used to prepare and activate amine-reactive esters of the carboxylate group to enable chemical binding. After a 20 min incubation at room temperature, EDC/NHS were eliminated under magnet separation. Beads were washed once with activation buffer and were resuspended in $500 \mu \mathrm{L}$ of the same buffer. Then, $50 \mu \mathrm{g}$ of R2 antipeptide antibodies was mixed with the beads on a shaker for $3.5 \mathrm{~h}$ to form R2 antipeptide antibody-beads. Subsequently, the coupled beads were washed twice and resuspended in storage buffer (PBS 1\% BSA and $0.05 \%$ of sodium azide) at a concentration of $2.10^{4}$ microspheres $/ \mu \mathrm{L}$ for storage.

The efficiency of coupling was tested by adding diluted (1:200) goat anti-rabbit Alexa fluor 488 into a tube containing $2.10^{4} \mathrm{mAb}$-coupled beads. After a $30 \mathrm{~min}$ incubation at $37^{\circ} \mathrm{C}$, beads were washed once with washing buffer (PBS $0.05 \%$ Tween 20), resuspended in $300 \mu \mathrm{L}$ PBS and analysed on a BD LSR Fortessa X-20 flow cytometer (BD Biosciences). Fluorescence emission was collected through 530/30 (FITC) bandpass filters. 


\section{Biotinylation of Detection Monoclonal Antibodies}

For detection antibody biotinylation, $1 \mathrm{~mL}$ of $10 \mathrm{mM}$ EZLink $^{\mathrm{TM}}$ NHS-SS-Biotin (Thermofisher) in DMSO was prepared in a first step. Next, the appropriate volume of biotin was added to S57S mAbs and the mixture was incubated at room temperature for $1 \mathrm{~h}$ prior to purification using a Zeba Desalt Spin Column (Thermofisher) to remove the unreacted biotin. The newly biotinylated S57S mAbs were then stored at $4{ }^{\circ} \mathrm{C}$.

\section{Microsphere-Based Assay}

One hundred $\mu \mathrm{L}$ of virus suspension was incubated with $2-4 \times 10^{3}$ antibody-coupled beads for $1 \mathrm{~h}$ at room temperature on a rocker. Virus-antibody-bead complexes were washed once with $200 \mu \mathrm{L}$ of washing buffer and resuspended in $50 \mu \mathrm{L}$ of incubation buffer beads (PBS $1 \%$ BSA and $0.2 \%$ Tween 20) and $1 \mu \mathrm{L}$ of biotinylated detection antibodies diluted in incubation buffer and were then incubated for $1 \mathrm{~h}$ at room temperature on a rocker. To eliminate excess free detection antibodies, the complexes were washed twice. Then, diluted PE-Cy5-conjugated streptavidin was added and incubated for $1 \mathrm{~h}$ at room temperature on a rocker. Before analysis, free PE-Cy5-conjugated streptavidin was discarded in two wash steps and the labelled complex was resuspended in $300 \mu \mathrm{L}$ of PBS. A filtered PBS sample was included in each experiment as negative control (background event recognition). All the experiments were performed in triplicate. Samples were analysed on a BD LSR Fortessa X-20 flow cytometer (BD Biosciences). Fluorescence emission was collected through 670/30 (PE-Cy5) bandpass filters. The data were processed with FlowJo, version V10.4.

\section{Statistical Analyses}

Statistical analyses were carried out using the $\mathrm{R}$ version 3.6.3 software. The normality of the data was tested using a Shapiro-Wilk test. Student's $t$ test was used to evaluate differences between mean fluorescence intensity of samples and the negative control. A one-way ANOVA was applied to estimate whether differences between mean fluorescence intensity were significant. A $P$ value less than 0.05 was considered significant.

\section{Results}

\section{Characterisation of R2 and R12 Antipeptide Antibodies Against Murine Norovirus and Human Norovirus}

Sera were characterised after rabbit immunisation with the 18 amino acid-large $\mathrm{S}$ domain peptide coupled to the
KLH carrier. MNV-1 CW1-infected RAW264.7 cells were detected by immunofluorescence using both R2 and R12 sera (Fig. 3A). Subsequently, both sera were purified and their cross-reactivity was demonstrated through an indirect ELISA assay wherein plates were coated with MNV isolate MNV-1 CW1 or HuNoV strains of different genotypes from stool samples (purified by ultracentrifugation to avoid competition between stool impurities and viral proteins). Both antipeptide antibodies were shown to have a higher affinity with MNV-1 CW1 when compared with different HuNoV genotypes. R2 antipeptide antibodies demonstrated reactivity against more HuNoV genotypes (GII.1, GII.2, GII.4, GII.14, GI.2 and GI.3) compared with R12 antipeptide antibodies, which did not react against HuNoV GII.1 and GII.2 (Fig. 3B).

\section{Immunoassay to Detect Human Norovirus}

Preliminary experiments mimicking the magnetic beadbased assay followed by flow cytometry were performed via a sandwich ELISA to detect HuNoV GI.3, GII.4 and GII.14. A weak positive signal was observed for GI.3 and GII.14 (Fig. 4). GII.4 detection, hitherto associated with a positive indirect ELISA result (Fig. 3B), was unsuccessful via the sandwich ELISA assay, this inconsistency indicating mAb L34D to be unsuited to GII.4 detection.

\section{Norovirus Detection by Flow Cytometry Implementing a Magnetic Bead-Based Immunoassay}

Magnetic beads were first coated and saturated with R2 or R12 capture antipeptide antibodies to avoid non-specific reactions and false-positive signals, and beads were saturated from $20 \mu \mathrm{g}$ of capture antibody concentration (Fig. 5). Magnetic beads coated with $50 \mu \mathrm{g}$ R2 antipeptide antibodies were used for the magnetic bead-based assay. The magnetic bead-based immunoassay in conjunction with flow cytometry was performed on HuNoV GI.3 faecal suspension. The highest mean fluorescence intensity (MFI) for GI.3 detection was $838( \pm 117)$ associated with $1.10^{8} \mathrm{gc} / \mathrm{mL}$; the fluorescence intensity decreased progressively with dilution, until reaching the detection limit of $15( \pm 1.4)$ MFI which corresponded to $5.10^{5} \mathrm{gc} / \mathrm{mL}$ in faecal suspension (Fig. 6A). For all tested dilutions, quantification of immunocaptured virus genome from faecal suspension showed genome copy values to be lesser than those in faecal suspension (Fig. 6A). Beadbound virus particle concentrations were reduced gradually with dilution of the virus suspension (Fig. 6A). As previously reported (Razafimahefa et al., 2021), high temperatures $\left(90{ }^{\circ} \mathrm{C}, 2 \mathrm{~min}\right)$ and prolonged exposure to UV light $(1 \mathrm{~h})$ 
$\mathbf{A}$

Pre-immune

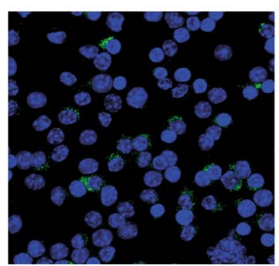

Immune
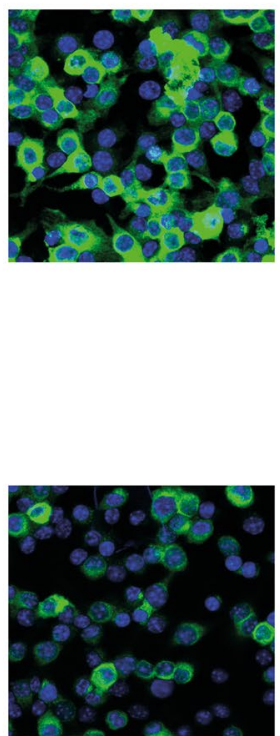

B

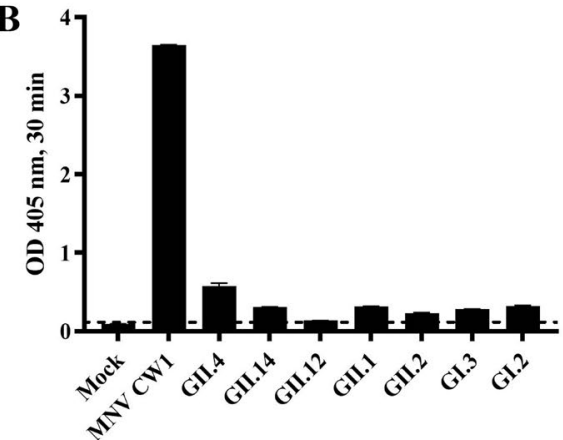

R2 antibodies

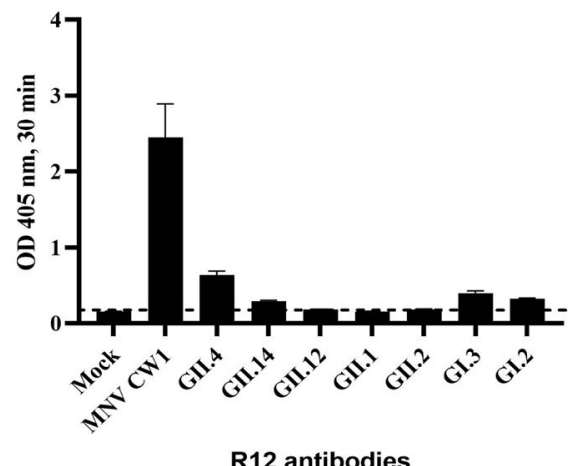

Fig. 3 R2 and R12 antipeptide antibodies cross-react with murine norovirus (MNV-1 CW1) and human noroviruses (HuNoVs) from different genotypes. A Reactivity of R2 (1:500) and R12 (1:200) sera against MNV infected RAW264.7 cells as determined by immunofluorescence. Pre-immune sera (1:100) were used as negative controls. B Cross-reactivity of purified R2 and R12 antipeptide antibod-
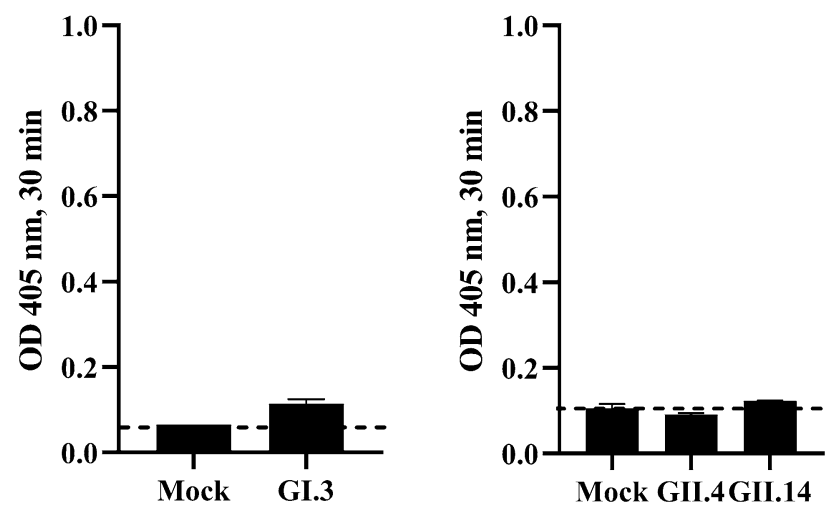

Fig. 4 Detection of GI.3, GII.4 and GII.14 human norovirus (HuNoV) in stool samples (dilution 1:10) by sandwich ELISA assay using the broadly reactive R2 and R12 antipeptide antibodies as capture antibodies and specific monoclonal antibodies S57S for GI and L34D for GII $(5 \mu \mathrm{g} / \mathrm{mL})$ as detection antibodies. The dashed line represents the mean absorbance values for the negative controls and indicates the threshold for a positive signal ies $(10 \mu \mathrm{g} / \mathrm{mL})$ against MNV-1 CW1 and purified HuNoVs from two genogroups (GI, GII) and different genotypes as determined by indirect ELISA assay. The dashed line represents the mean absorbance values for the negative controls and indicates the threshold for a positive signal

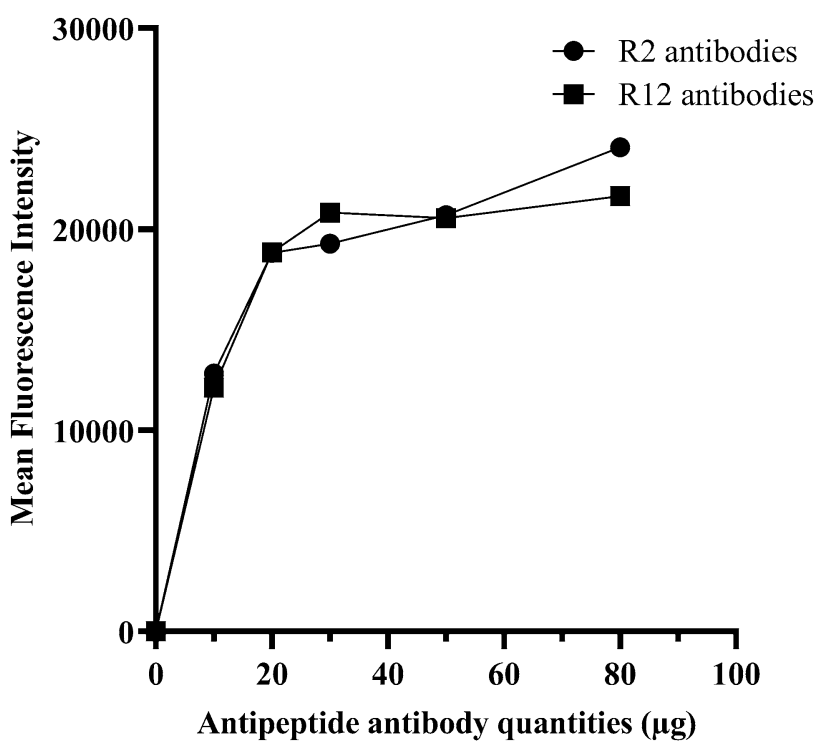

Fig. 5 Mean fluorescence intensity depending on the saturation of magnetic beads with different quantities of R2 or R12 antipeptide antibodies 


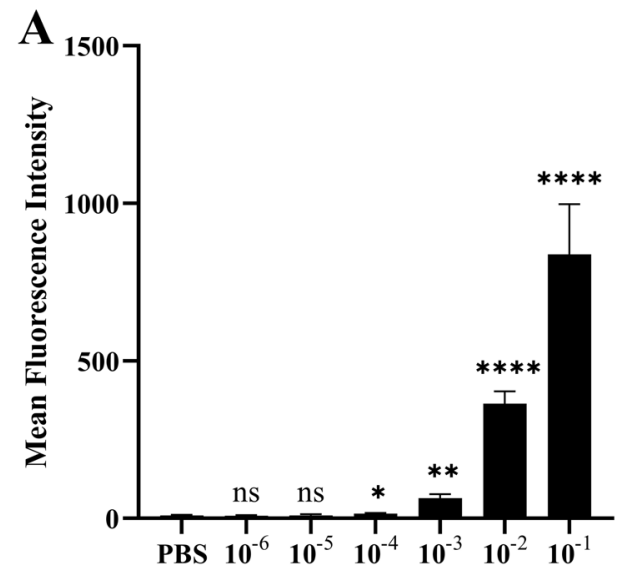

GI.3 dilution

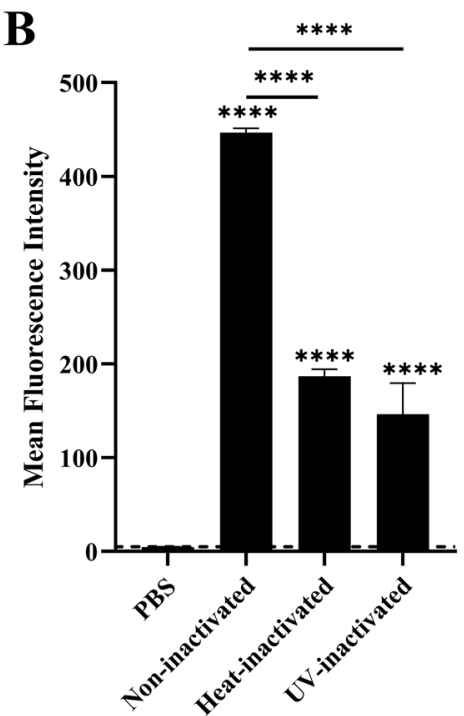

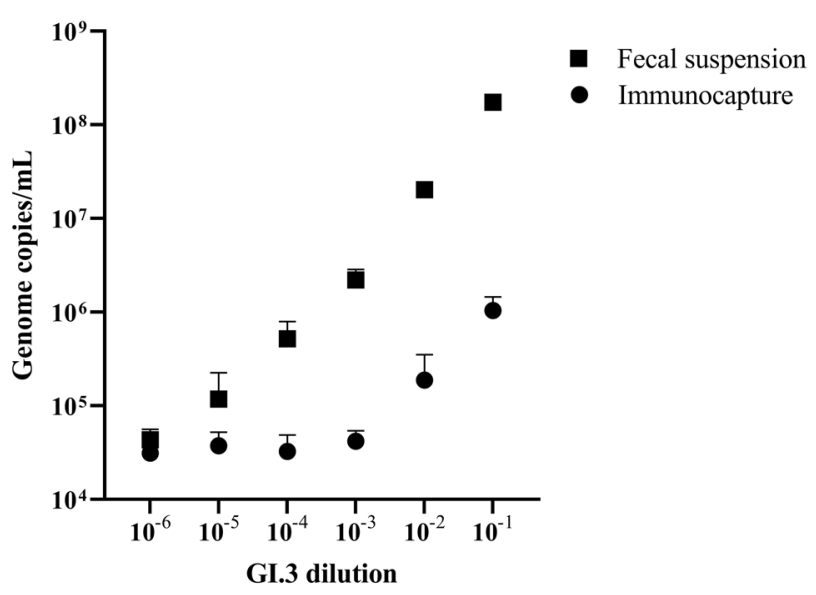

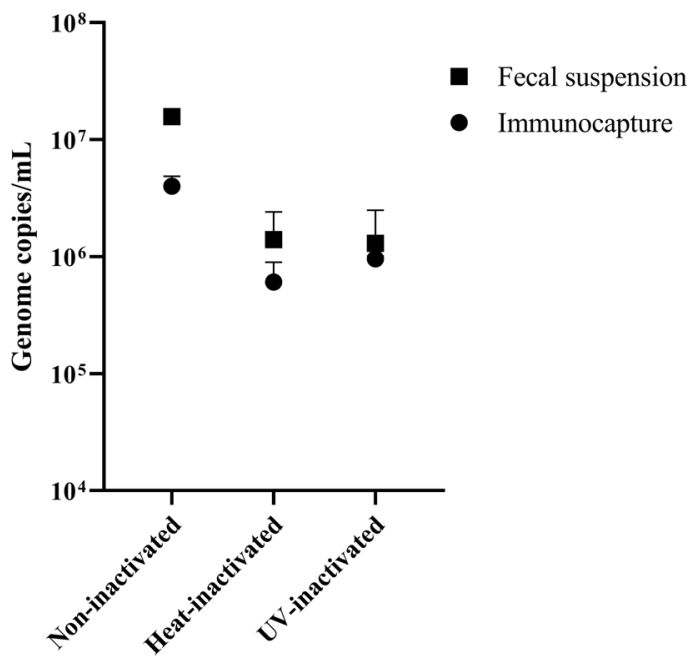

Fig. 6 GI.3 human norovirus (HuNoV) detection in faecal suspension by flow cytometry (histogram and mean of fluorescence intensity (MFI)). A Detection of different dilutions of GI.3 HuNoV in faeces and comparison between the quantification of genomic copies in faecal suspension or after immunocapture. The limit of detection (LoD) was the genome copy quantity of the dilution corresponding to the last significant dilution compared with the negative control after flow cytometry analysis. B Detection of non-inactivated, heat-inactivated $\left(90{ }^{\circ} \mathrm{C}, 2 \mathrm{~min}\right)$ and UV-inactivated (1 h) GI.3 HuNoV and comparison between the quantification of genomic copies in faecal suspension or after immunocapture. The threshold value for virus detection by flow cytometry was the value of the negative control: PBS. Gating controls are shown in Figure S1 and S2. Statistical significance: ${ }^{*} p \leq 0.05 ; * * p \leq 0.01 ; * * * * p \leq 0.0001$

increased. Both curves of virus genome concentrations from spiked mussels and immunocapture of virus from spiked mussels intersect: the magnetic beads coated with $\mathrm{R} 2$ antipeptide antibodies showed a concentration effect when virus concentrations were under $10^{5} \mathrm{gc} / \mathrm{mL}$. After spiking of mussel DTs with infectious or inactivated GI.3, the signal was positive for all samples, whilst a significant reduction of the fluorescence intensity was remarked for inactivated GI.3 (as in faecal suspensions) treatments (Fig. 7B). At the same time, genome copy values also decreased in spiked DTs. The concentration effect of R2 antibody-coated beads was also observed for inactivated GI.3, when RNA copies were under $10^{5} \mathrm{gc} / \mathrm{mL}$. 


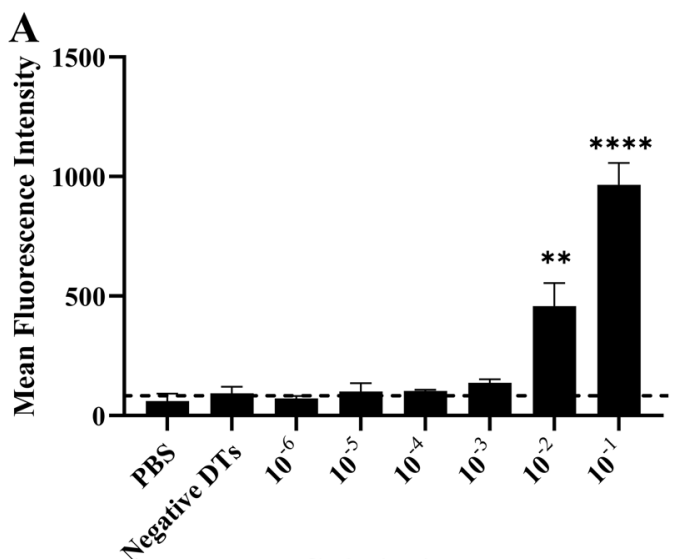

GI.3 dilution

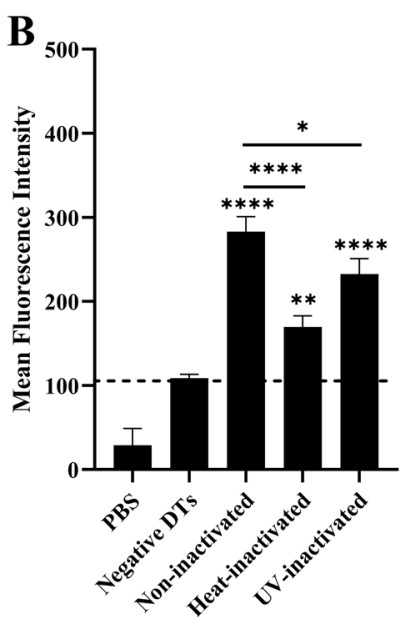

Fig. 7 Detection of GI.3 human norovirus (HuNoV) in mussel digestive tissues (DTs) by flow cytometry (histogram and mean of fluorescence intensity (MFI)). A Detection by flow cytometry of GI.3 HuNoV diluted in mussel DTs supernatants and comparison between the quantification of genomic copies in faecal suspension or after immunocapture. The limit of detection (LoD) was the genome copy quantity of the dilution corresponding to the last significant dilution compared with negative control after flow cytometry analysis.

The gating strategies employed during the flow cytometry analyses for each experiment are shown in four supplementary figures (Figure S1-S4). Each plot shows the position of the gate for the starting population (i.e. the bead population); this fraction of events is expressed as a percentage of the total events, where an event corresponds to the detection of a single bead. All virus-bead populations were considered for the histograms and the calculation of the mean fluorescence intensity (MFI).

\section{Discussion}

Ranging in size from 27 to $38 \mathrm{~nm}$ in diameter, NoV particles are significantly below the typical 300-500 nm detection limits for common flow cytometry instruments (Steen,

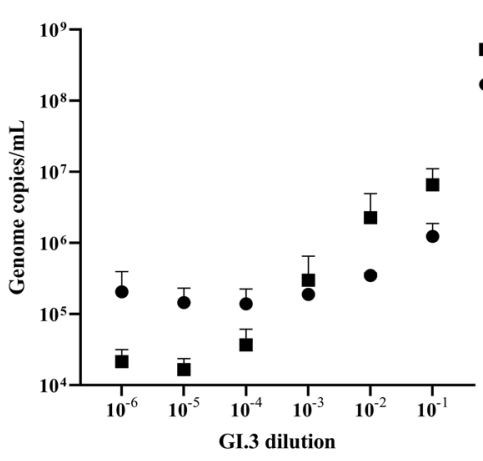

Spiked digestive tissues

- Immunocapture

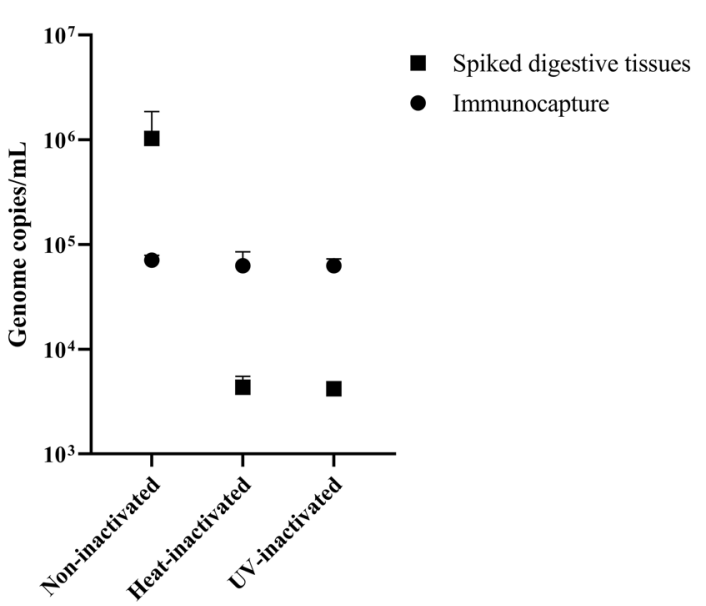

B Detection of non-inactivated, heat-inactivated $\left(90{ }^{\circ} \mathrm{C}, 2 \mathrm{~min}\right)$ and UV-inactivated (1 h) GI.3 HuNoV spiked in mussel DTs and comparison between genomic copies quantification in faecal suspension or after immunocapture. The threshold value for virus detection by flow cytometry was the value of negative control: negative mussel DTs supernatant. Gating controls are shown in Figure S3 and S4. Statistical significance: ${ }^{*} p \leq 0.05 ; * * p \leq 0.01 ; * * * * p \leq 0.0001$

2004). This study contributes meaningfully to the development of a flow cytometry approach to detect HuNoVs in the context of routine detection, allowing for analysis of multiple samples per day and yielding immediate results regarding potential viral contamination. Firstly, we generated broadly reactive antipeptide antibodies against the $\mathrm{S}$ domain of the viral capsid protein. Secondly, we developed a magnetic bead-based immunoassay where magnetic beads were coated and saturated with the newly generated antipeptide antibodies. Finally, we utilised an adapted bead-based assay in a flow cytometry approach aimed at HuNoV GI.3 detection in stool and spiked food samples.

The $\mathrm{S}$ domain is an ideal target for the production of broadly reactive anti-NoV antibodies due to its high conservation across NoV genogroups (Prasad et al., 1999; 
Vongpunsawad et al., 2013). Both epitopes contained in the peptides are the residues IDPWI and WIRNNF. All mAbs recognising these epitopes (previously produced from viruslike particles (VLPs) or recombinant NoV capsid protein) have been shown to be broadly reactive (Li et al., 2009; Parra et al., 2013). Most cross-reactive mAbs that recognise various NoV genogroups have been reported to target the S domain and P1 domain (Crawford et al., 2015; Hansman et al., 2012; Huang et al., 2014; Li et al., 2009; Parker et al., 2005; Parra et al., 2013; Zheng et al., 2018). However, since the $\mathrm{S}$ domain is localised at the capsid interior, parts of it can be less accessible to antibodies. The $\mathrm{P}$ domain has recently been shown to support two conformations (Smith \& Smith, 2019), namely the rising conformation as evidenced in MNV (Katpally et al., 2008), HuNoV GII.10 (Hansman et al., 2012) and GII.4 (Devant et al., 2019), where the P domain rises from the $\mathrm{S}$ domain surface, and the resting conformation as represented by GI.1 (Prasad et al., 1999) and GII.2 viruses (Jung et al., 2019), where the P domain rests upon the $\mathrm{S}$ domain. Moreover, dynamic conformational changes have been reported for $\mathrm{MNV}$ and $\mathrm{HuNoV}$ GII.3; whilst the MNV conformational changes have been reported in response to aqueous conditions (the $\mathrm{P}$ domain rises from the $\mathrm{S}$ domain surface in solutions with higher $\mathrm{pH}$ and rests in solutions with lower $\mathrm{pH}$ (Song et al., 2020)), the mechanism is yet unclear for GII.3 viruses. The accessibility of $\mathrm{S}$ domain epitopes may be inferred from the dynamic rotation of the $\mathrm{P}$ domain. Interestingly, the antipeptide antibody developed against the $\mathrm{S}$ domain was shown to be reactive against MNV-1 CW1 and to a lesser extent to several HuNoV strains in stool samples (GII.4, GII.14, GII.1, GII.2, GI.3 and GI.2) by an indirect ELISA.

The characterisation of antipeptide antibody R2 was also performed with a sandwich ELISA. This experiment mimics the magnetic bead-based immunoassay in its setup. Our results suggest that broadly reactive antipeptide antibody $\mathrm{R} 2$ is suitable for NoV capture being able to detect intact NoV particles. The mAb N2C3 that targets residues WIRNNF has previously been reported to be able to detect native $\mathrm{HuNoV}$ in stool samples (Li et al., 2009). In an effort to develop a flow cytometry approach for HuNoV detection in varying samples, we implemented magnetic beads coated with R2 antipeptide antibodies. Virus detection by flow cytometry is typically based on fluorescence such as using fluorescent antibodies directed against surface antigens to detect viruses. Therefore, the high specificity and affinity of antibodies towards their antigens is required. Herein, the high affinity between biotin and streptavidin was instrumentalised for the purpose of labelling. Our magnetic bead-based immunoassay in conjunction with flow cytometry, as tested both on biological waste and spiked food matrices, can detect HuNoVs in different samples. We showed that fluorescence intensity varies with the virus particle concentrations in both matrices. The detection limit of our flow cytometry approach as applied to stool samples was $10^{5} \mathrm{gc} / \mathrm{mL}$, rendering it more sensitive than the commercial rapid test currently utilised for $\mathrm{HuNoV}$ detection in biological samples, which presents a detection limit of $10^{7}$ to $10^{8}$ copies $/ \mathrm{mL}$ (Khamrin et al., 2015; Ushijima et al., 2017). Importantly, this reduced LoD has the potential to allow detection at the lower end of the reported range of typical faecal shedding (patients may excrete from $10^{5}$ to $10^{11}$ virus particles per gram of stool (Atmar et al., 2008)); this approach may thus provide a powerful tool for HuNoV diagnosis in clinical laboratory settings.

At $10^{6} \mathrm{gc} / \mathrm{mL}$, the LoD for HuNoV GI.3 in spiked mussel DTs was elevated. Since the concentration of HuNoVs in aquatic environments can range from 50 to $10^{6} \mathrm{gc} / \mathrm{L}$ (Hassard et al., 2017) and in shellfish from $10^{2}$ to $10^{4} \mathrm{gc} / \mathrm{g}$ of DT (Stals et al., 2012), further optimisation of the approach is required to enhance the sensitivity of the method in its application to food and environmental samples. We suggest that a high affinity between epitopes and antibodies (capture and detection) will be amongst the key determinants for future improvement of the approach, based on our observations that a stronger biotin-streptavidin interaction has already proven more efficacious than weak antibody-secondary antibody interactions for detection and staining. In this context, the identification of more accessible P1 and P2 subdomain epitopes for the generation of capture antibodies and the identification of specific epitopes for individual genogroups for the production of antipeptide detection antibodies may lead to an important improvement. Moreover, synthetic peptides are a rapid and useful tool to produce broadly reactive anti-norovirus antibodies after identifying a conservative site. In the case of complex matrices such as shellfish, the virus elution and concentration step from the complex samples is also a critical step to be considered for further detection limit optimisation of the flow cytometry assay in mussels. The advantage of using antipeptide antibodies coupled to magnetic beads is that this method not only allows for detection of virus particles during flow cytometry analysis but also permits an immunoconcentration and purification by removing traces of debris from complex matrices such as food samples and biological samples.

Using short peptides (18-mer peptide) for immunisation involves the generation of antipeptide antibodies that recognise linear epitopes. Here, we demonstrate that such antipeptide antibodies can bind native $\mathrm{HuNoV}$ in stool samples; we suggest that the epitopes in question are probably located on the surface of the folded $\mathrm{S}$ domain and are thus exposed. Detection of inactivated HuNoVs coincides with a notable decrease of fluorescence intensity; we attribute the observed signal decrease associated with inactivated viruses to conformational changes of the capsid surface which may have served to "hide" underlying epitopes, rendering them 
inaccessible for capture with antipeptide antibodies. Since the epitopes correspond to only a small portion of the capsid, the alteration of this portion itself is unknown. Continued capture of inactivated HuNoVs by R2 antipeptide antibodycoated magnetic beads was also confirmed via genome quantification. Virus inactivation treatments can cause capsid damage and can lead to the genome release (Razafimahefa et al., 2021). Here, the antibodies used to capture and detect virus via flow cytometry can only recognise a small portion of the capsid, namely short, targeted epitopes. We suggest that these epitopes are still recognised by antibodies even though the genome is released. Since a positive flow cytometry signal is thus not necessarily indicative of an "intact" virus (capsid enclosing a genome), RT-qPCR should be performed for genome quantification.

Whilst flow cytometry has previously been applied to the detection of viruses in general, and recently to NoV VLPs in particular through binding to commensal bacteria (Madrigal \& Jones, 2020), this study provides the first report on direct detection of viable HuNoVs via the magnetic bead-based immunoassay in conjunction with flow cytometry approach and thus serves as a proof-of-concept regarding the feasibility of NoV detection via flow cytometry. The method may further provide information regarding remaining intact structural motives of detected viruses; future improvements will thus include not only the identification of more easily accessible (conserved) P1 or P2 subdomain peptides but also an investigation into the link between particle detection and determination of virus infectivity.

\section{Conclusion}

Antipeptide antibodies coupled to magnetic beads were able to capture MNV and diverse $\mathrm{HuNoV}$ particles. A magnetic bead-based immunoassay followed by flow cytometry analysis was capable of detecting HuNoVs in biological waste and food samples. The usefulness of our flow cytometry approach was proven in biological waste samples; the approach will be easily optimisable for application to food and environmental samples. Immunomagnetic capture may also be used as concentration method to isolate and enrich NoVs from environmental (large volumes) and food (complex matrices) samples which may contain only low virus amounts. The proposed flow cytometry approach may serve as a prototype tool for the development of an immediate and sensitive method for routine $\mathrm{HuNoV}$ screening in biological, environmental and food samples and for confirmation and quantification during outbreak investigations.

Supplementary Information The online version contains supplementary material available at https://doi.org/10.1007/s12560-021-09494-w.
Acknowledgements We thank Dr Pascale Huynen (Liège CHU, Belgium), Dr Bavo Verhaegen and Dr Katelijne Dierick (Sciensano, Brussels, Belgium) for providing clinical samples. This project was supported by a Grant from the Service Public Fédéral 'Santé Publique, Sécurité de la Chaîne alimentaire et Environnement' (RT15/8 IQUINOR2) (R.M.R, L. F. L.-B., E. T.).

\section{References}

Arakelyan, A., Fitzgerald, W., Margolis, L., \& Grivel, J.-C. (2013). Nanoparticle-based flow virometry for the analysis of individual virions. Journal of Clinical Investigation, 123(9), 3716-3727. https://doi.org/10.1172/JCI67042

Atmar, R. L., \& Estes, M. K. (2006). The Epidemiologic and Clinical Importance of Norovirus Infection. Gastroenterology Clinics of North America, 35(2), 275-290. https://doi.org/10.1016/j.gtc. 2006.03.001

Atmar, R. L., Opekun, A. R., Gilger, M. A., Estes, M. K., Crawford, S. E., Neill, F. H., \& Graham, D. Y. (2008). Norwalk virus shedding after experimental human infection. Emerging Infectious Diseases, 14(10), 1553-1557. https://doi.org/10.3201/eid1410. 080117

Brussaard, C. P. D., Marie, D., \& Bratbak, G. (2000). Flow cytometric detection of viruses. Journal of Virological Methods, 85(1-2), 175-182. https://doi.org/10.1016/S0166-0934(99)00167-6

Chhabra, P., de Graaf, M., Parra, G. I., Chan, M. C. W., Green, K., Martella, V., et al. (2019). Updated classification of norovirus genogroups and genotypes. The Journal of General Virology, 100(10), 1393-1406. https://doi.org/10.1099/jgv.0.001318

Crawford, S. E., Ajami, N., Parker, T. D., Kitamoto, N., Natori, K., Takeda, N., Tanaka, T., Kou, B., Atmar, R. L., \& Estes, M. K. (2015). Mapping broadly reactive norovirus genogroup i and II monoclonal antibodies. Clinical and Vaccine Immunology, 22(2), 168-177. https://doi.org/10.1128/CVI.00520-14

Devant, J., Hofhaus, G., \& Hansman, G. S. (2019). Novel structural features of human norovirus capsid. bioRxiv. https://doi.org/10. $1101 / 528240$

Dolin, R., Blacklow, N. R., DuPont, H., Buscho, R. F., Wyatt, R. G., Kasel, J. A., Hornick, R., \& Chanock, R. M. (1972). Biological properties of Norwalk agent of acute infectious nonbacterial gastroenteritis. Experimental Biology and Medicine, 140(2), 578-583. https://doi.org/10.3181/00379727-140-36508

El Bilali, N., Duron, J., Gingras, D., \& Lippé, R. (2017). Quantitative Evaluation of Protein Heterogeneity within Herpes Simplex Virus 1 Particles. Journal of Virology. https://doi.org/10.1128/ jvi.00320-17

Fuller, R. R., \& Sweedler, J. V. (1996). Characterizing submicron vesicles with wavelength-resolved fluorescence in flow cytometry. Cytometry, 25(2), 144-155. https://doi.org/10.1002/(SICI) 1097-0320(19961001)25:2\%3c144::AID-CYTO3\%3e3.0.CO;2-H

Glass, R. I., Parashar, U. D., \& Estes, M. K. (2009). Norovirus gastroenteritis. New England Journal of Medicine, 361(18), 1776. https://doi.org/10.1056/NEJMra0804575

Gozalbo-Rovira, R., Rubio-Del-Campo, A., Santiso-Bellón, C., VilaVicent, S., Buesa, J., Delgado, S., Molinero, N., Margolles, A., Yebra, M. J., Collado, M. C., Monedero, V., \& Rodríguez-Díaz, J. (2021). Interaction of Intestinal bacteria with human rotavirus during infection in children. International Journal of Molecular Sciences, 22(3), 1010. https://doi.org/10.3390/ijms22031010

Hansman, G. S., Taylor, D. W., McLellan, J. S., Smith, T. J., Georgiev, I., Tame, J. R. H., Park, S. Y., Yamazaki, M., Gondaira, F., Miki, M., Katayama, K., Murata, K., \& Kwong, P. D. (2012). Structural basis for broad detection of genogroup II noroviruses by 
a monoclonal antibody that binds to a site occluded in the viral particle. Journal of Virology, 86(7), 3635-3646. https://doi.org/ 10.1128/jvi.06868-11

Hardy, M. E. (2005). Norovirus protein structure and function. FEMS Microbiology Letters, 253(1), 1-8. https://doi.org/10.1016/J. FEMSLE.2005.08.031

Hassard, F., Sharp, J. H., Taft, H., LeVay, L., Harris, J. P., McDonald, J. E., Tuson, K., Wilson, J., Jones, D. L., \& Malham, S. K. (2017). Critical review on the public health impact of norovirus contamination in shellfish and the environment: A UK perspective. Food and Environmental Virology, 9(2), 123-141. https://doi.org/10. 1007/s12560-017-9279-3

Huang, W., Samanta, M., Crawford, S. E., Estes, M. K., Neill, F. H., Atmar, R. L., \& Palzkill, T. (2014). Identification of human singlechain antibodies with broad reactivity for noroviruses. Protein engineering design and selection (Vol. 27, pp. 339-349). Oxford University Press.

Iannelli, D. (1996). Cytofluorimetric method for the detection of the cucumber mosaic virus. Phytopathology, 86(9), 959. https://doi. org/10.1094/Phyto-86-959

Iannelli, D., D’Apice, L., Cottone, C., Viscardi, M., Scala, F., Zoina, A., Del Sorbo, G., Spigno, P., \& Capparelli, R. (1997). Simultaneous detection of cucumber mosaic virus, tomato mosaic virus and potato virus Y by flow cytometry. Journal of Virological Methods, 69(1-2), 137-145. https://doi.org/10.1016/S0166-0934(97) 00149-3

Jiang, X., Wang, M., Graham, D. Y., \& Estes, M. K. (1992). Expression, self-assembly, and antigenicity of the Norwalk virus capsid protein. Journal of Virology, 66(11), 6527-6532. https://doi.org/ 10.1128/jvi.66.11.6527-6532.1992

Jung, J., Grant, T., Thomas, D. R., Diehnelt, C. W., Grigorieff, N., \& Joshua-Tor, L. (2019). High-resolution cryo-EM structures of outbreak strain human norovirus shells reveal size variations. Proceedings of the National Academy of Sciences of the United States of America, 116(26), 12828-12832. https://doi.org/10.1073/pnas. 1903562116

Kapikian, A. Z., Wyatt, R. G., Dolin, R., Thornhill, T. S., Kalica, A. R., \& Chanock, R. M. (1972). Visualization by immune electron microscopy of a 27-nm particle associated with acute infectious nonbacterial gastroenteritis. Journal of virology, 10(5), 1075-81. http://www.ncbi.nlm.nih.gov/pubmed/4117963. Accessed 30 July 2018

Katpally, U., Wobus, C. E., Dryden, K., Virgin, H. W., \& Smith, T. J. (2008). Structure of antibody-neutralized murine norovirus and unexpected differences from viruslike particles. Journal of Virology, 82(5), 2079-2088. https://doi.org/10.1128/jvi.02200-07

Khamrin, P., Thongprachum, A., Takanashi, S., Okitsu, S., Maneekarn, N., Hayakawa, S., \& Ushijima, H. (2015). Evaluation of immunochromatography tests for detection of novel GII.17 norovirus in stool samples. Eurosurveillance. https://doi.org/10.2807/15607917.ES2015.20.28.21185

Kim, B. C., Ju, M. K., Dan-Chin-Yu, A., \& Sommer, P. (2009). Quantitative detection of HIV-1 particles using HIV-1 neutralizing antibody-conjugated beads. Analytical Chemistry, 81(6), 2388-2393. https://doi.org/10.1021/ac802267u

Kolawole, A. O., Xia, C., Li, M., Gamez, M., Yu, C., Rippinger, C. M., Yucha, R. E., Smith, T. J., \& Wobus, C. E. (2014). Newly isolated $\mathrm{mAbs}$ broaden the neutralizing epitope in murine norovirus. Journal of General Virology, 95(Pt 9), 1958-1968. https://doi.org/10. 1099/vir.0.066753-0

Lambden, P. R., Caul, E. O., Ashley, C. R., \& Clarke, I. N. (1993). Sequence and genome organization of a human small round-structured (Norwalk-like) virus. Science, 259(5094), 516-519. https:// doi.org/10.1126/science.8380940

Le Guyader, F. S., Parnaudeau, S., Schaeffer, J., Bosch, A., Loisy, F., Pommepuy, M., \& Atmar, R. L. (2009). Detection and quantification of noroviruses in shellfish. Applied and Environmental Microbiology, 75(3), 618-624. https://doi.org/10.1128/ AEM.01507-08

Li, X., Zhou, R., Tian, X., Li, H., \& Zhou, Z. (2010). Characterization of a cross-reactive monoclonal antibody against Norovirus genogroups I, II, III and V. Virus Research, 151(2), 142-147. https:// doi.org/10.1016/J.VIRUSRES.2010.04.005

Li, X., Zhou, R., Wang, Y., Sheng, H., Tian, X., Li, H., \& Qiu, H. (2009). Identification and characterization of a native epitope common to norovirus strains GII/4, GII/7 and GII/8. Virus Research, 140(1-2), 188-193. https://doi.org/10.1016/J.VIRUS RES.2008.12.004

Loisy, F., Atmar, R. L., Guillon, P., Le Cann, P., Pommepuy, M., \& Le Guyader, F. S. (2005). Real-time RT-PCR for norovirus screening in shellfish. Journal of Virological Methods, 123(1), 1-7. https:// doi.org/10.1016/j.jviromet.2004.08.023

Loret, S., El Bilali, N., \& Lippé, R. (2012). Analysis of herpes simplex virus type I nuclear particles by flow cytometry. Cytometry Part A, 81A(11), 950-959. https://doi.org/10.1002/cyto.a.22107

Ludwig-Begall, L. F., Mauroy, A., \& Thiry, E. (2018). Norovirus recombinants: Recurrent in the field, recalcitrant in the lab-a scoping review of recombination and recombinant types of noroviruses. The Journal of General Virology, 99(8), 970-988. https:// doi.org/10.1099/jgv.0.001103

Madrigal, J. L., \& Jones, M. K. (2020). Quantifying human norovirus virus-like particles binding to commensal bacteria using flow cytometry. Journal of Visualized Experiments, 2020(158), e61048. https://doi.org/10.3791/61048

Mallory, M. L., Lindesmith, L. C., Graham, R. L., \& Baric, R. S. (2019). GII.4 human norovirus: Surveying the antigenic landscape. Viruses. https://doi.org/10.3390/v11020177

Mead, P. S., Slutsker, L., Dietz, V., McCaig, L. F., Bresee, J. S., Shapiro, C., Griffin, P. M., \& Tauxe, R. V. (1999). Food-related illness and death in the United States. Emerging Infectious Diseases, 5(5), 607-625. https://doi.org/10.3201/eid0505.990502

Parker, T. D., Kitamoto, N., Tanaka, T., Hutson, A. M., \& Estes, M. K. (2005). Identification of Genogroup I and Genogroup II broadly reactive epitopes on the norovirus capsid. Journal of Virology, 79(12), 7402-7409. https://doi.org/10.1128/jvi.79.12.7402-7409. 2005

Parra, G. I., Azure, J., Fischer, R., Bok, K., Sandoval-Jaime, C., Sosnovtsev, S. V., Sander, P., \& Green, K. Y. (2013). Identification of a broadly cross-reactive epitope in the inner shell of the norovirus capsid. PLoS ONE, 8(6), e67592. https://doi.org/10.1371/journal. pone. 0067592

Prasad, B. V. V., Hardy, M. E., Dokland, T., Bella, J., Rossmann, M. G., \& Estes, M. K. (1999). X-ray crystallographic structure of the Norwalk virus capsid. Science, 286(5438), 287-290. https://doi. org/10.1126/science.286.5438.287

Razafimahefa, R. M., Ludwig-Begall, L. F., Le Guyader, F. S., Farnir, F., Mauroy, A., \& Thiry, E. (2021). Optimisation of a PMAxx ${ }^{\mathrm{TM}}$-RT-qPCR assay and the preceding extraction method to selectively detect infectious murine norovirus particles in mussels. Food and Environmental Virology, 13, 93-106. https://doi. org/10.1007/s12560-020-09454-w

Reed, L. J., \& Muench, H. (1938). A simple method of estimating fifty per cent endpoints12. American Journal of Epidemiology, 27(3), 493-497. https://doi.org/10.1093/oxfordjournals.aje.a118408

Ruis, C., Roy, S., Brown, J. R., Allen, D. J., Goldstein, R. A., \& Breuer, J. (2017). The emerging GII.P16-GII.4 Sydney 2012 norovirus lineage is circulating worldwide, arose by late-2014 and contains polymerase changes that may increase virus transmission. PLoS ONE. https://doi.org/10.1371/journal.pone.0179572

Schindelin, J., Arganda-Carreras, I., Frise, E., Kaynig, V., Longair, M., Pietzsch, T., Preibisch, S., Rueden, C., Saalfeld, S., Schmid, B., Tinevez, J. Y., White, D. J., Hartenstein, V., Eliceiri, K., 
Tomancak, P., \& Cardona, A. (2012). Fiji: An open-source platform for biological-image analysis. Nature Methods, 9(7), 676682. https://doi.org/10.1038/nmeth.2019

Siebenga, J. J., Vennema, H., Zheng, D. P., Vinjé, J., Lee, B. E., Pang, X. L., Ho, E. C., Lim, W., Choudekar, A., Broor, S., Halperin, T., Rasool, N. B., Hewitt, J., Greening, G. E., Jin, M., Duan, Z. J., Lucero, Y., O'Ryan, M., Hoehne, M., \& Koopmans, M. (2009). Norovirus illness is a global problem: Emergence and spread of norovirus GII.4 variants, 2001-2007. The Journal of Infectious Diseases, 200(5), 802-812. https://doi.org/10.1086/605127

Smith, H. Q., \& Smith, T. J. (2019). The dynamic capsid structures of the noroviruses. Viruses. https://doi.org/10.3390/v11030235

Song, C., Takai-Todaka, R., Miki, M., Haga, K., Fujimoto, A., Ishiyama, R., Oikawa, K., Yokoyama, M., Miyazaki, N., Iwasaki, K., Murakami, K., Katayama, K., \& Murata, K. (2020). Dynamic rotation of the protruding domain enhances the infectivity of norovirus. PLoS Pathogens. https://doi.org/10.1371/journal.ppat. 1008619

Stals, A., Baert, L., Coillie, E. V., \& Uyttendaele, M. (2012). Extraction of food-borne viruses from food samples: A review. International Journal of Food Microbiology, 153(1-2), 1-9. https://doi.org/10. 1016/j.jifoodmicro.2011.10.014

Steen, H. B. (2004). Flow cytometer for measurement of the light scattering of viral and other submicroscopic particles. Cytometry, 57A(2), 94-99. https://doi.org/10.1002/cyto.a.10115

Svraka, S., Duizer, E., Vennema, H., De Bruin, E., Van Der Veer, B., Dorresteijn, B., \& Koopmans, M. (2007). Etiological role of viruses in outbreaks of acute gastroenteritis in The Netherlands from 1994 through 2005. Journal of Clinical Microbiology, 45(5), 1389-1394. https://doi.org/10.1128/JCM.02305-06

Tan, M., Fang, P., Chachiyo, T., Xia, M., Huang, P., Fang, Z., Jiang, W., \& Jiang, X. (2008). Noroviral P particle: Structure, function and applications in virus-host interaction. Virology, 382(1), 115-123. https://doi.org/10.1016/j.virol.2008.08.047

Tang, V. A., Renner, T. M., Varette, O., Le Boeuf, F., Wang, J., Diallo, J. S., Bell, J. C., \& Langlois, M. A. (2016). Single-particle characterization of oncolytic vaccinia virus by flow virometry. Vaccine, 34(42), 5082-5089. https://doi.org/10.1016/j.vaccine.2016.08.074

Thackray, L. B., Wobus, C. E., Chachu, K. A., Liu, B., Alegre, E. R., Henderson, K. S., Kelley, S. T., \& Virgin, H. W. (2007). Murine noroviruses comprising a single genogroup exhibit biological diversity despite limited sequence divergence. Journal of virology, 81(19), 10460-73. https://doi.org/10.1128/JVI.00783-07

Tracy, B. P., Gaida, S. M., \& Papoutsakis, E. T. (2010). Flow cytometry for bacteria: Enabling metabolic engineering, synthetic biology and the elucidation of complex phenotypes. Current Opinion in Biotechnology, 21(1), 85-99. https://doi.org/10.1016/j.copbio. 2010.02.006
Ushijima, H., Thongprachum, A., Khamrin, P., Takanashi, S., Okitsu, S., Maneekarn, N., \& Hayakawa, S. (2017). Evaluation of immunochromatographic tests and a new enzyme immunoassay for detection of a novel GII.17 norovirus in stool samples. Japanese Journal of Infectious Diseases, 70(3), 326-328. https://doi.org/ 10.7883/yoken.JJID.2016.413

Vongpunsawad, S., Venkataram Prasad, B. V., \& Estes, M. K. (2013). Norwalk virus minor capsid protein VP2 associates within the VP1 shell domain. Journal of Virology, 87(9), 4818-4825. https:// doi.org/10.1128/JVI.03508-12

Vorauer-Uhl, K., Wagner, A., Borth, N., \& Katinger, H. (2000). Determination of liposome size distribution by flow cytometry. Cytometry, 39(2), 166-171. https://doi.org/10.1002/(SICI)10970320(20000201)39:2\%3c166::AID-CYTO10\%3e3.0.CO;2-M

Yan, X., Schielke, E. G., Grace, K. M., Hassell, C., Marrone, B. L., \& Nolan, J. P. (2004). Microsphere-based duplexed immunoassay for influenza virus typing by flow cytometry. Journal of Immunological Methods, 284(1-2), 27-38. https://doi.org/10.1016/j.jim. 2003.09.016

Yan, X., Zhong, W., Tang, A., Schielke, E. G., Hang, W., \& Nolan, J. P. (2005). Multiplexed flow cytometric immunoassay for influenza virus detection and differentiation protein detection. A FourPlexed Assay for Influenza Virus Was Developed to Demonstrate the Potential for Multi-, 77(23), 7673-7678.

Yang, S.-Y., Lien, K.-Y., Huang, K.-J., Lei, H.-Y., \& Lee, G.-B. (2008). Micro flow cytometry utilizing a magnetic bead-based immunoassay for rapid virus detection. Biosensors and Bioelectronics, 24, 855-862. https://doi.org/10.1016/j.bios.2008.07.019

Yoda, T., Suzuki, Y., Terano, Y., Yamazaki, K., Sakon, N., Kuzuguchi, T., Oda, H., \& Tsukamoto, T. (2003). Precise characterization of norovirus (Norwalk-like virus)-specific monoclonal antibodies with broad reactivity. Journal of Clinical Microbiology, 41(6), 2367-2371. https://doi.org/10.1128/JCM.41.6.2367-2371.2003

Zheng, L., Wang, W., Liu, J., Chen, X., Li, S., Wang, Q., Huo, Y., Qin, C., Shen, S., \& Wang, M. (2018). Characterization of a Norovirusspecific monoclonal antibody that exhibits wide spectrum binding activities. Journal of Medical Virology, 90(4), 671-676. https:// doi.org/10.1002/jmv.25001

Zicari, S., Arakelyan, A., Fitzgerald, W., Zaitseva, E., Chernomordik, L. V., Margolis, L., \& Grivel, J. C. (2016). Evaluation of the maturation of individual Dengue virions with flow virometry. Virology, 488, 20-27. https://doi.org/10.1016/j.virol.2015.10.021

Publisher's Note Springer Nature remains neutral with regard to jurisdictional claims in published maps and institutional affiliations.

\section{Authors and Affiliations}

\section{Ravo M. Razafimahefa ${ }^{1}$. Louisa F. Ludwig-Begall ${ }^{1}$. Mamadou Amadou Diallo ${ }^{2} \cdot$ Benjamin G. Dewals ${ }^{2}$. Alain Vanderplasschen ${ }^{2} \cdot$ Olivier Nivelles $^{2} \cdot$ Caroline Deketelaere $^{2} \cdot$ Axel Mauroy $^{3} \cdot$ Etienne Thiry $^{1}(0)$}

Etienne Thiry

etienne.thiry@uliege.be

1 Veterinary Virology and Animal Viral Diseases, Department of Infectious and Parasitic Diseases, Faculty of Veterinary Medicine, FARAH Research Centre, Liège University, B43b, Quartier Vallée 2, Avenue de Cureghem, 10, B-4000 Liège, Belgium
2 Immunology-Vaccinology, Department of Infectious and Parasitic Diseases, Faculty of Veterinary Medicine, FARAH Research Centre, Liège University, B43b, Quartier Vallée 2, Avenue de Cureghem, 10, B-4000 Liège, Belgium

3 Staff Direction for Risk Assessment, Control Policy, Federal Agency for the Safety of the Food Chain, Bld du Jardin Botanique 55, B-1000 Brussels, Belgium 